\title{
Research and Application of Power Detection Technology on Photovoltaic Module Array
}

\author{
Zhang Zhen tao*, Li Gang, Zou Ping guo, Li Qiang, Chen Ya bin \\ Suzhou Nuclear Power Research Institute Co. Ltd.,1788 XihuanRoad, Suzou, P.R.China, 215004
}

\begin{abstract}
Based on the principle of photovoltaic module power detection, an intelligent module array power detection scheme is proposed, and a photovoltaic module array power detection device is designed. It consists of a master and multiple slaves. The voltage, current, temperature, and irradiation signals are synchronously collected and processed by acquisition module CC2530, and then wirelessly transmitted to the host for processing through zigbee communication protocol. These signals are calculated and displayed by the host software. Photovoltaic module array power detection device adopts modular design and experience experimental test. The measurement error meets the needs of field test. The device has the advantages of convenient portability, simple operation, high informatization, large test range, and good safety.
\end{abstract}

\section{Introduction}

Photovoltaic power generation, as an important form of new energy, has been used more and more widely at home and abroad. Its core component is photovoltaic module, which is responsible for the functions of photoelectric conversion and power output. Module power test and attenuation calculation are extremely important for the construction and maintenance of power stations [1]. Damage and attenuation of photovoltaic module arrays [2, $3]$ will not only result in the decline of power generation capacity, but also more security risks will be caused during the operation of the power station $[4,5]$. For the power detection of photovoltaic module arrays, at present, there is no relevant technical method in China that can directly perform accurate measurements. Each testing agency measures multiple physical quantities and makes records, and then the results are obtained through subsequent calculations [6]. Due to the inconsistencies in the frequency of different physical quantity acquisition instruments, there is no correlation among the physical quantities, and the entire test process requires multiple people to operate, which is not only cumbersome but also low in safety.

Based on the principle of photovoltaic module array power detection (PMPD), this paper proposes an intelligent module array power detection scheme, and then develops detection equipment to synchronously collect current, voltage, temperature, and irradiation signals, and obtain power values after processing, transmission, and automatic calculation.

\section{Detection principle}

The DC system power test only needs to measure the product of current and voltage, but the power of photovoltaic modules is greatly affected by temperature and irradiation. In order to accurately measure the realtime power of photovoltaic module arrays and the power under standard conditions, accurate detection of irradiation, voltage, current and temperature is necessary, and then power is calculated with the power-temperature coefficient of photovoltaic module. The powertemperature coefficient of battery used by each module is relatively stable and can be considered as a constant.

The standard test condition (STC) of the module is: light intensity, $1000 \mathrm{~W} / \mathrm{m}^{2}$; spectrum, $1.5 \mathrm{~A}$; module temperature, $25^{\circ} \mathrm{C}$. In the case of STC, the formula for calculating the power of photovoltaic module is as follows:

$$
P_{S T C}=U \cdot I \cdot \frac{1000}{I_{r r}} \cdot\left[1+\gamma \cdot\left(T_{1}-T_{2}\right)\right]
$$

In the formula, $P_{\mathrm{STC}}$ is the power converted to the standard state; $U$ is tested module voltage; $I$ means tested module current; $I_{\mathrm{rr}}$ means tested module plane irradiation; $\gamma$ is module power-temperature coefficient, generally negative; $T_{2}$ is tested module temperature; $T_{1}$ is the temperature under standard state.

According to formula (1), the standard state power test of photovoltaic module arrays needs to measure four physical quantities and input the power-temperature coefficient to calculate the power in standard state. To this end, an intelligent module power detection scheme is proposed, that is, synchronously collecting irradiation, voltage, current, and temperature signal, and then centralized display module array power after wireless

\footnotetext{
*Corresponding author: zhangzhentao@cgnpc.com.cn
} 
transmission and calculation. The technical route of the intelligent detection scheme is shown in Figure 1.

The key to completing the intelligent power detection system is to solve the problems of data transmission and sample sampling. In the system design, we give priority to solving the communication module scheme, and then determine the sampling module based on the communication scheme selection.

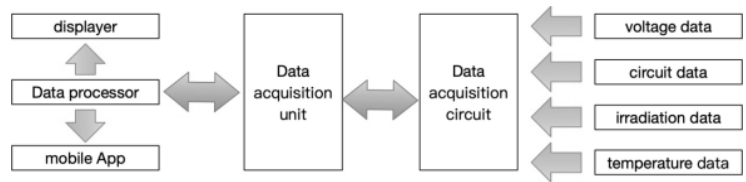

Fig.1. Technical route

\section{Detection system development}

\subsection{Communication module design}

Photovoltaic power stations are mostly built in mountains, lakes and deserts. The environment of photovoltaic module arrays is complex. To facilitate on-site detection, wireless transmission is used for signal transmission. At present, the three widely used wireless communication methods are Wifi, Zigbee, and Bluetooth. The above three transmission methods are analyzed from the dimensions of transmission distance, transmission power consumption, transmission rate, and network nodes. The comparison results are shown in Table 1.

In order to cope with the complex test environment, the detection equipment should have the characteristics of low power consumption, large test range and multiple nodes. So Zigbee is the best choice based on the above analysis.

Table 1. Analysis of wireless transmission methods

\begin{tabular}{|c|c|c|c|c|}
\hline $\begin{array}{c}\text { Commun } \\
\text { ication } \\
\text { type }\end{array}$ & $\begin{array}{c}\text { Transmis } \\
\text { sion } \\
\text { distance }\end{array}$ & $\begin{array}{c}\text { Power } \\
\text { consump } \\
\text { tion }\end{array}$ & $\begin{array}{c}\text { Transmis } \\
\text { sion rate }\end{array}$ & $\begin{array}{c}\text { Network } \\
\text { node }\end{array}$ \\
\hline WiFi & $30-100 \mathrm{~m}$ & $10-50 \mathrm{~mW}$ & $\leq 11 \mathrm{Mbps}$ & 32 \\
\hline ZigBee & $10-100 \mathrm{~m}$ & $5 \mathrm{~m} \mathrm{~W}$ & $\begin{array}{c}20 \sim \\
250 \mathrm{kbps}\end{array}$ & $\begin{array}{c}\text { Up to } \\
65000\end{array}$ \\
\hline Bluetooth & $2-10 \mathrm{~m}$ & $\begin{array}{c}\text { Between } \\
\text { zigbee } \\
\text { and WiFi }\end{array}$ & $\leq 3 \mathrm{Mbps}$ & 8 \\
\hline
\end{tabular}

The devices in the ZigBee network are mainly divided into three types: Coordinator, which is mainly responsible for the establishment and maintenance of the wireless network; Router, which is mainly responsible for the routing of wireless network data, being understood as the signal relay; End device, which mainly implements data collection in wireless networks. The PMPD equipment only needs a coordinator and an end device.

The CC2530 introduced by Texas Instruments (TI) is an industry-leading Zigbee solution. It comes with an industry-standard enhanced 8051CPU, 8KB programmable flash memory in the system, and 8 input ports. It can be used as a communication chip for power detection equipment.

According to the selection of the communication chip, an intelligent power detection system scheme was formulated. Irradiation sampling module, temperature sampling module, voltage sampling module and current sampling module, all achieved by Zigbee module, each module wirelessly transmits the acquisition signal to the Zigbee coordinator. The schematic diagram of the system is shown in Figure 2.

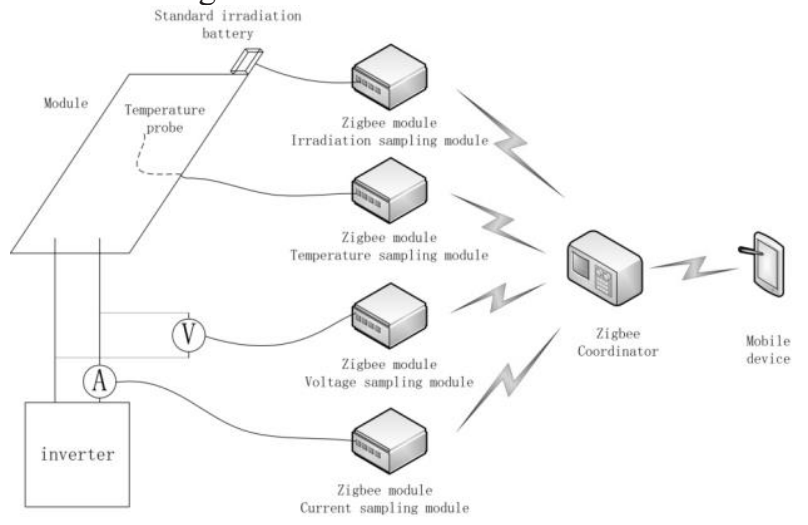

Fig.2. Scheme of power detection system '

\subsection{Data sampling module design}

The data signals that need to be sampled in the field power test include voltage, current, irradiation and temperature. The sampling signal is input to the acquisition module CC2530 after being processed by the sampling circuit. CC2530 chip has 8 input ports, 12-bit resolution, and supports $0 \sim 3.3 \mathrm{~V}$ voltage input. According to the selection of CC2530 chip, we accomplished the circuit schematic diagram, and select the sensor and signal processing method.

(1) Voltage signal acquisition: The voltage-dividing resistor circuit is connected in series at the output end of the photovoltaic module array to collect the voltage signal. The system voltage is 0 to $1500 \mathrm{~V}$. The output signal is 0 to $3 \mathrm{~V} \mathrm{DC}$ voltage through the sampling circuit and directly connected to the acquisition module ADC interface.

(2) Current signal acquisition: Select the highprecision DC current clamp Fluki1010 to collect the current signal at the output end of the photovoltaic module array. The collected current signal is converted into a $\mathrm{mV}$ voltage signal by $1 \mathrm{Mv} / 1 \mathrm{~A}$, and then amplified 15 times and then input to the ADC interface of the acquisition module.

(3) Irradiation signal acquisition: Select the German GMC solar radiation measuring instrument, place it on the surface of the test module array and maintain the same inclination angle to perform the irradiation signal acquisition. The collected irradiation signal is converted into a $\mathrm{mV}$ voltage signal by a signal amplifier at $100 \mathrm{mV} / 1000 \mathrm{~W} / \mathrm{m}^{2}$, and then amplified by 30 times and then input to the acquisition module ADC interface.

(4) Temperature signal acquisition: The temperature sensor is placed on the back panel of test module, and two acquisition methods can be used: a. Numerical module DS18B20 temperature sensor, temperature test range $-55^{\circ} \mathrm{C}$ 
$\sim+125{ }^{\circ} \mathrm{C}$, with the characteristic of small size, antiinterference ability and high precision; b. Using thermocouple and thermal resistance sensor, the output is converted into a current signal at $4-20 \mathrm{~mA} /-25 \sim 135^{\circ} \mathrm{C}$, and then connected to a $200 \Omega$ resistor, which is converted into a $0.8 \sim 4 \mathrm{~V}$ signal and input to the ADC interface of the acquisition module. The field test temperature is below $100^{\circ} \mathrm{C}$, and the actual signal does not exceed $3.3 \mathrm{~V}$.

\subsection{Software Development}

After the communication module and data sampling module finished, we initiate software development. The CC2530 chip released by TI supports the Zigbee protocol, whose development environment is IAR Embedded Workbench.

According to the formulated system scheme, the development is performed according to the mode of one master and four slaves, so as to determine the acquisition module firmware program and the master firmware program. The program flow of the master and four slaves is shown in Figure 3 and the data flow is as shown in Figure 4.
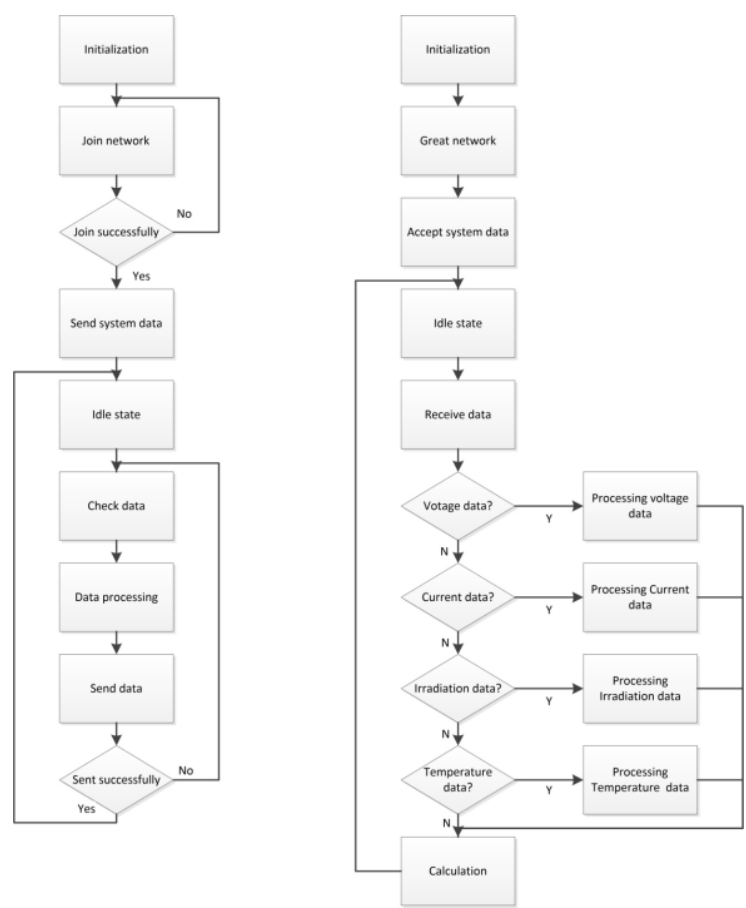

Fig.3. Program flow of slave and master

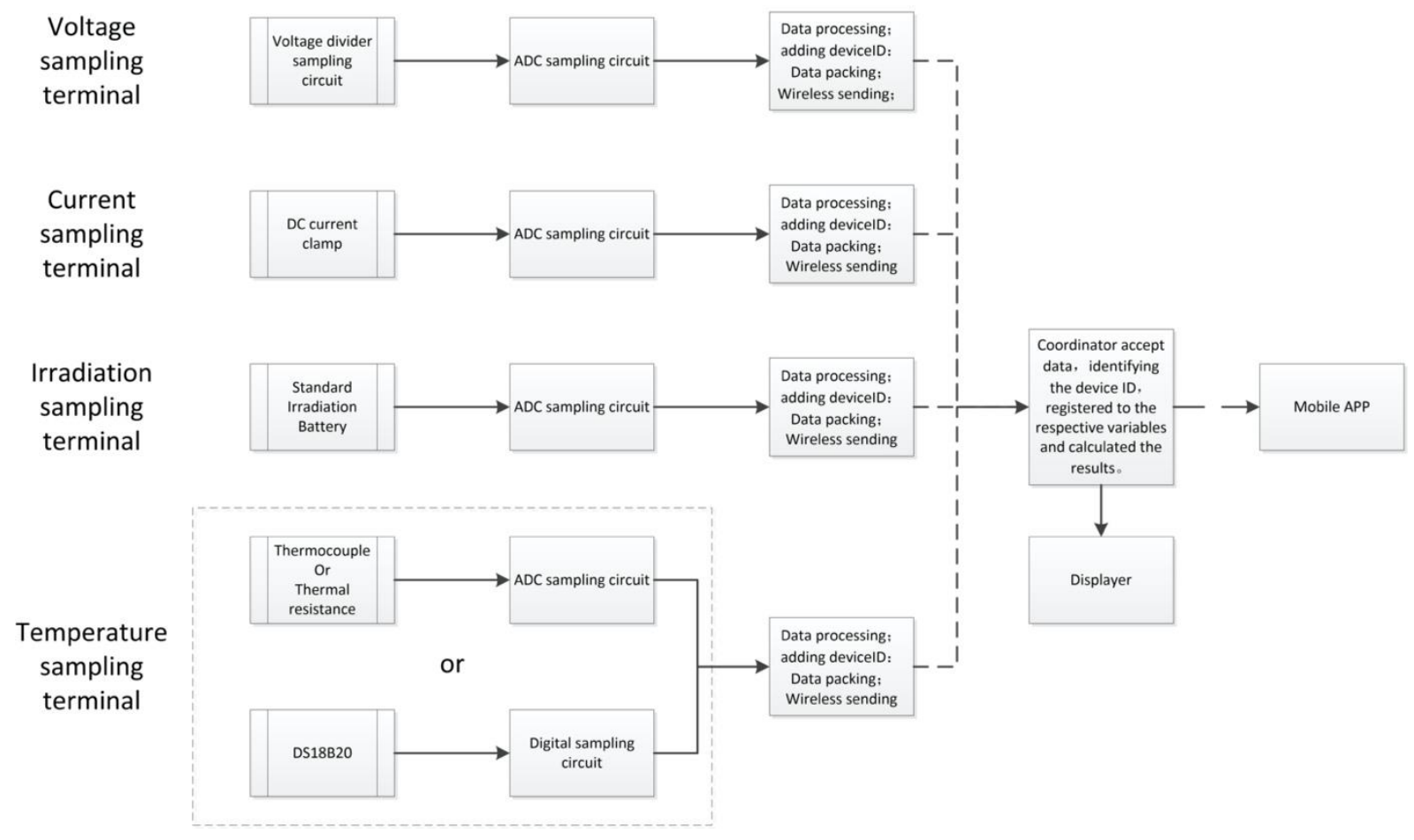

Fig.4. Data flow of slave and master

\section{Development of detection device}

\subsection{Composition of detection device}

The circuit was developed in accordance with the above research ideas and adopted a modular design, which mainly includes a power module, two signal amplifier modules, a temperature transmitter module, a communication module, and an auxiliary circuit module. The main functions of each module are shown in Table 2, and figure 5 expresses the intelligent detection device system. 
Table 2. Module composition and function

\begin{tabular}{|c|c|}
\hline Module name & Features \\
\hline Power Management Module & $\begin{array}{c}\text { Charge and boost the voltage of lithium } \\
\text { battery }\end{array}$ \\
\hline DCDC module & Increase the voltage of lithium batteries \\
\hline Signal amplification module 1 & Amplify the current signal by 10 times \\
\hline Signal amplification module 2 & Amplify the current signal by 30 times \\
\hline Temperature transmitter module & $\begin{array}{c}\text { Converts thermal resistance or thermocouple } \\
\text { signals into } 4-20 \mathrm{~mA} \text { signals }\end{array}$ \\
\hline Communication module & $\begin{array}{l}\text { Responsible for transmitting signals, } \\
\text { calculations and displays }\end{array}$ \\
\hline Auxiliary circuit module & $\begin{array}{l}\text { Power module external filter circuit; } \\
\text { temperature transmitter external circuit; } \\
\text { module power supply interface }\end{array}$ \\
\hline
\end{tabular}

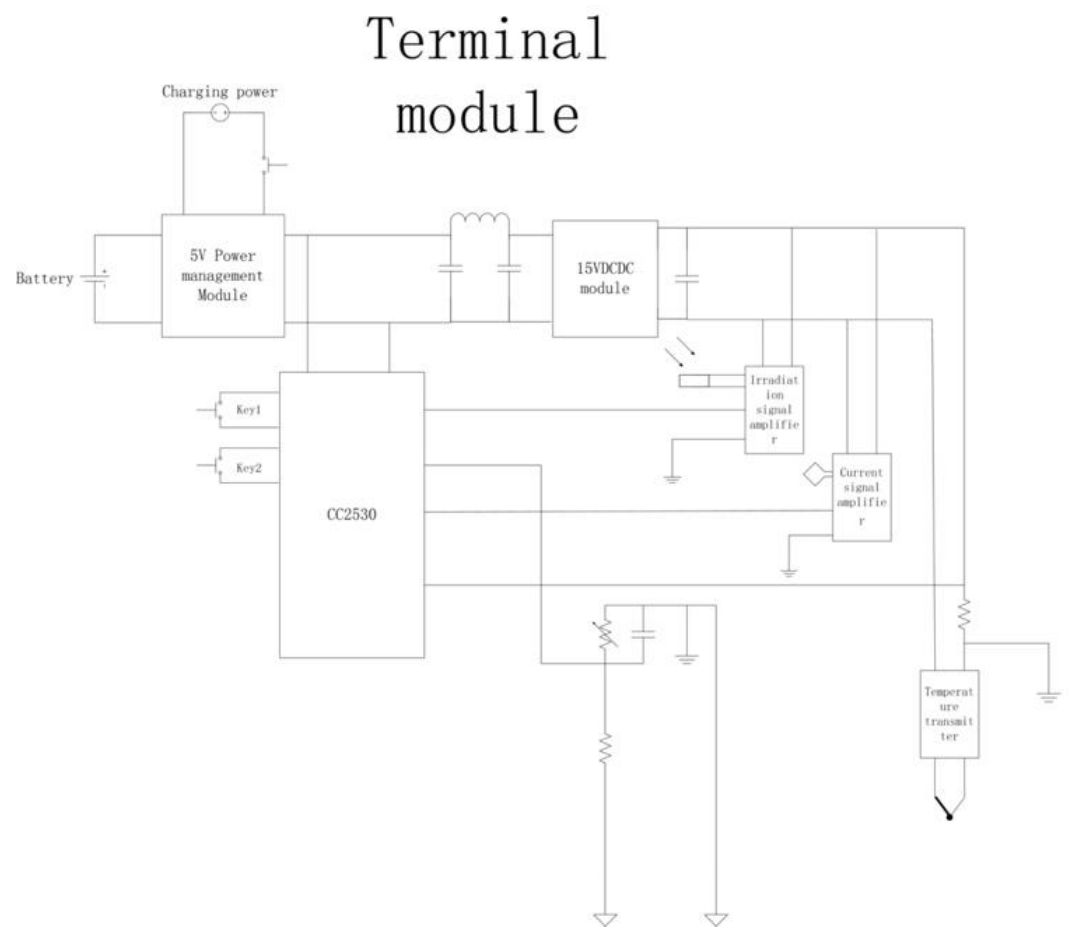

\section{Host module}

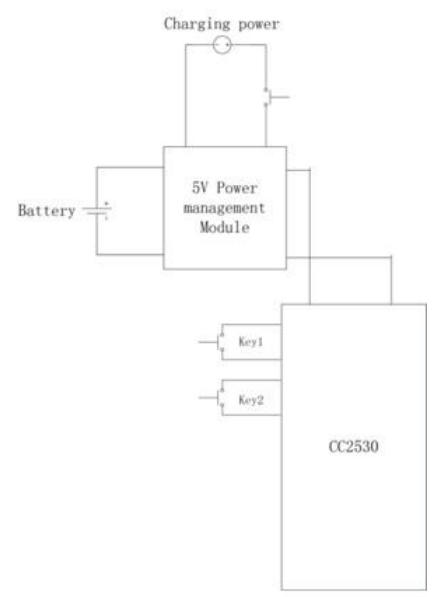

Fig.5. System diagram of detection device

The above components are purchased and the circuit layout is performed, and then the structure of the data acquisition module and the host module is determined. Figure 6 shows the circuit layout.

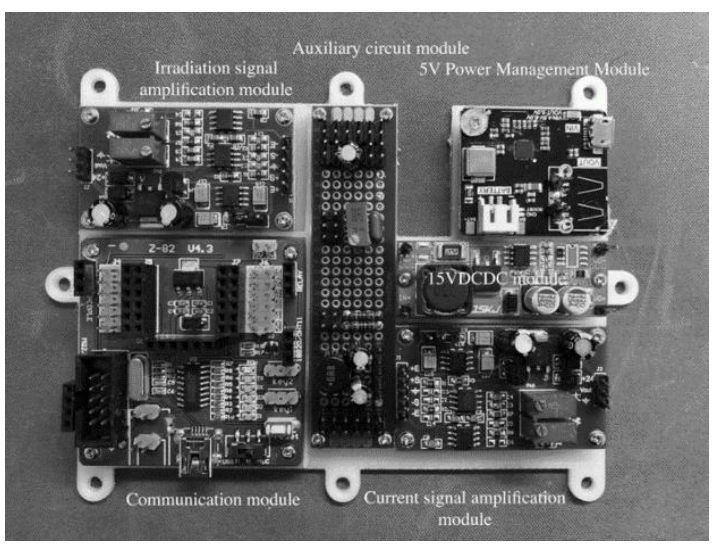

Fig.6. Circuit layout

\subsection{Detection device test}

The detection device is shown in Figure 7. The signal simulator is used for laboratory test of the power detection device. Connect the voltage, current, irradiation, and temperature sensors to the corresponding ports of the same data collector. After the device communicates successfully, the detection device can display the voltage, current, irradiation, temperature and module powertemperature coefficient, and calculate the data to display the real-time power and module power under modified STC conditions. Adjust the power-temperature coefficient and wait for $5 \mathrm{~s}$, after the calculated result is stable, the data is recorded as table 3 . 


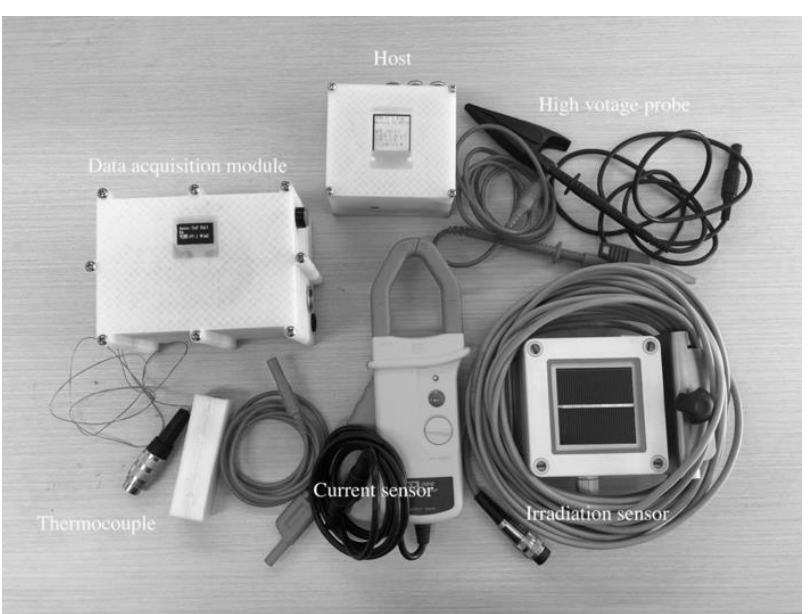

Fig.7. Detection device

Table 3. Test data record

\begin{tabular}{|c|c|c|c|c|c|}
\hline $\begin{array}{l}\text { Signal } \\
\text { type }\end{array}$ & $\begin{array}{c}\text { Analog } \\
\text { signal }\end{array}$ & $\begin{array}{c}\text { Signal } \\
\text { of } \\
\text { signal } \\
\text { generat } \\
\text { or }\end{array}$ & $\begin{array}{c}\text { Collecto } \\
\mathrm{r} \\
\text { display }\end{array}$ & $\begin{array}{c}\text { Host } \\
\text { display }\end{array}$ & $\begin{array}{l}\text { Deviati } \\
\text { on }\end{array}$ \\
\hline $\begin{array}{c}\text { Irradiati } \\
\text { on }\end{array}$ & $\begin{array}{l}299.7 \\
\mathrm{~W} / \mathrm{m}^{2}\end{array}$ & $900 \mathrm{mV}$ & $\begin{array}{l}290.3 \\
\mathrm{~W} / \mathrm{m}^{2}\end{array}$ & $\begin{array}{l}290.3 \\
\mathrm{~W} / \mathrm{m}^{2}\end{array}$ & $3 \%$ \\
\hline $\begin{array}{l}\text { Irradiati } \\
\text { on }\end{array}$ & $\begin{array}{c}333 \\
\mathrm{~W} / \mathrm{m}^{2}\end{array}$ & $\begin{array}{c}1000 \mathrm{~m} \\
\mathrm{~V}\end{array}$ & $\begin{array}{l}323.6 \\
\mathrm{~W} / \mathrm{m}^{2}\end{array}$ & $\begin{array}{l}323.6 \\
\mathrm{~W} / \mathrm{m}^{2}\end{array}$ & $3 \%$ \\
\hline $\begin{array}{l}\text { Irradiati } \\
\text { on }\end{array}$ & $\begin{array}{c}666 \\
\mathrm{~W} / \mathrm{m}^{2}\end{array}$ & $\begin{array}{c}2000 \mathrm{~m} \\
\mathrm{~V}\end{array}$ & $\begin{array}{l}658.4 \\
\mathrm{~W} / \mathrm{m}^{2}\end{array}$ & $\begin{array}{l}658.4 \\
\mathrm{~W} / \mathrm{m}^{2}\end{array}$ & $1 \%$ \\
\hline $\begin{array}{l}\text { Irradiati } \\
\text { on }\end{array}$ & $\begin{array}{c}999 \\
\mathrm{~W} / \mathrm{m}^{2}\end{array}$ & $\begin{array}{c}3000 \mathrm{~m} \\
\mathrm{~V}\end{array}$ & $\begin{array}{l}992.8 \\
\mathrm{~W} / \mathrm{m}^{2}\end{array}$ & $\begin{array}{l}992.8 \\
\mathrm{~W} / \mathrm{m}^{2}\end{array}$ & $1 \%$ \\
\hline voltage & $500 \mathrm{~V}$ & $\begin{array}{c}1000 \mathrm{~m} \\
\mathrm{~V}\end{array}$ & $487.0 \mathrm{~V}$ & $487.0 \mathrm{~V}$ & $3 \%$ \\
\hline voltage & $1000 \mathrm{~V}$ & $\begin{array}{c}2000 \mathrm{~m} \\
\mathrm{~V}\end{array}$ & $986.5 \mathrm{~V}$ & $986.5 \mathrm{~V}$ & $1 \%$ \\
\hline voltage & $1500 \mathrm{~V}$ & $\begin{array}{c}3000 \mathrm{~m} \\
\mathrm{~V}\end{array}$ & $\begin{array}{c}1486.9 \\
V\end{array}$ & $\begin{array}{c}1486.9 \\
\mathrm{~V}\end{array}$ & $1 \%$ \\
\hline current & $90 \mathrm{~A}$ & $900 \mathrm{mV}$ & $88.9 \mathrm{~A}$ & $88.9 \mathrm{~A}$ & $1 \%$ \\
\hline current & $100 \mathrm{~A}$ & $\begin{array}{c}1000 \mathrm{~m} \\
\mathrm{~V}\end{array}$ & $99.4 \mathrm{~A}$ & $99.4 \mathrm{~A}$ & $1 \%$ \\
\hline current & $200 \mathrm{~A}$ & $\begin{array}{c}2000 \mathrm{~m} \\
\mathrm{~V}\end{array}$ & $201.3 \mathrm{~A}$ & $201.3 \mathrm{~A}$ & $-1 \%$ \\
\hline current & $300 \mathrm{~A}$ & $\begin{array}{c}3000 \mathrm{~m} \\
\mathrm{~V}\end{array}$ & $303.1 \mathrm{~A}$ & $303.1 \mathrm{~A}$ & $-1 \%$ \\
\hline
\end{tabular}

It can be known from the test results that the minimum distortion of the device is the sensor signal between $1 \mathrm{~V}$ and $3.3 \mathrm{~V}$, and this interval exactly includes the normal working state of the photovoltaic module, which meets the needs of field test. This determines the applicable range of PMPD device: voltage of 600 to $1500 \mathrm{~V}$, working current of $100 \mathrm{~A}$ to $300 \mathrm{~A}$, irradiation of $333 \mathrm{~W} / \mathrm{m}^{2}$ to $1100 \mathrm{~W} / \mathrm{m}^{2}$, test temperature of 0 to $135^{\circ} \mathrm{C}$ and the effective distance of the sensor is $30 \mathrm{~m}$.

\section{Conclusion}

In this paper, an intelligent PMPD device is designed. It consists of a master and four slaves. Using zigbee communication protocol, the voltage, current, temperature, and irradiation signals are collected and processed synchronously through the acquisition module CC2530. The signal is transmitted to the host for processing, and the result is calculated and displayed by the host software.

PMPD device adopts modular design, mainly composed of power management module, DCDC module, signal amplifier module, temperature transmitter module, communication module, auxiliary circuit module and so on. This equipment has been tested in laboratory, and the measurement error meets the needs of field test. PMPD device has the advantages of simple operation, informatization, convenient carrying, large test range, high security, rich interfaces, and good expansion performance.

\section{References}

1. SONG Hao, CHEN Haomin, WANG Yi, YUN Min. Power Measurement of Bifacial Photovoltaic Modules [J].Physical Testing and Chemical Analysis Part A: Physical Testing, 2018, 54(1), 20-24.

2. GAO Yuan, ZHANG Jietan, SUN Guangyou etc. Standard and method of power generation attenuation test for PV modules [J]. Qinghai Electric Power, 2017, 36(2), 32-35.

3. HUANG Yue-wen, CAO Hua-xiang, LIU Shuai etc. Degradation analysis of monocrystalline silicon PV modules [J]. Chinese Journal of Power Sources, 2019, 43 (4) , 641-645.

4. ZHAO Mingzhi, SUN Hao, MIAO Yiming. Wind Tunnel Experimental Study on the Influence of Sand Accumulation on the Output Characteristics of PV Modules [J]. Journal Of Chinese Society Of Power Engineering, 2019, 29 (9), 765-769.

5. LIU Zhen-bo, CHAN Bing-bing. Studying of power degradation and hot spots about PV modules $[\mathrm{J}]$. Chinese Journal of Power Sources, 2018, 42 (8) ,1177-1179.

6. LAI Qitao. Design of Electrical Control System of High Precision Photovoltaic Component Tester [J]. Process Automation Instrumentation, 2019, 40(1), 24-26. 